Turismo. Primera edición. p. 75-BELLON, Edna y MOLINA, Rosa. (2002) Gestión y desarrollo turístico regional. Bogotá. p. 125

- Carta del Turismo Sostenible. del 24 al 29 de Abril, 1995, Conferencia Mundial del Turismo Sostenible. Realizada en Lanzarote, Islas Canarias, España.

- MELLER KRUMHOLZ Daniel, Turismo y Desarrolio Sostenible, 2002 Universidad

Externado de Colombia, , pag 11-12)

- ACERENZA, Miguel Angel, , 2006 ,Editorial Trillas pag 81.

- http://www. world-tourism. org/susta inable/esp/top/concepts. html

- León http://fclm.com/fdmescyl/index.php/senderismo/

\title{
ESTADO DEL ARTE DEL SECTOR ECONÓMICO DEL MEDIO AMBIENTE
}

\author{
Carod Johanna Otero Gómez \\ Grupo de Investigación IDEAS
}

La creciente preocupación por el deterioro ambiental causado por la acción del hombre ha generado el surgimiento de una serie de actividades ambientales empresariales que buscan mitigar dichos impactos, hoy ya se habla en algunos países europeos del sector económico emergente del medio ambiente. En nuestro país el tema se encuentra poco explorado y por ello se plantea la realización del estado del arte del sector económico del medio ambiente en Europa y Colombia, identificando los hitos que dieron origen al sector y las variables económicas $y$ sociales que influyeron en su desarrollo, además de establecer como se encuentra Colombia en materia económica ambiental.

Palabras clave: Sector económico, negocios ambientales, empresas ambientales, bienes y servicios ambientales.

En un principio, buscando información para crear una empresa cuyo objetivo fuera la prestación de servicios de consultoría ambiental, se empezó a cruzar por mí camino una serie de estudios e información (vía internet) con títulos como "Empleo y formación en el sector del medioambiente en España", el sector medioambiental en España o la asociación de empresas medioambientales de Andalucía AESMA, o noticias como "La industria medioambiental española mueve 10.000 millones cada año, según el ICEX" y algunos indicadores de empleo del llamado sector emergente del medioambiente, en ese momento el tema me llamo la atención așí que decidí iniciar una búsqueda de dicho sector en Colombia, sin embargo la información al respecto fue insuficiente. 
En efecto, la problemática mundial relacionada con el medioambiente dio origen a una serie de actividades que buscan mitigar los impactos negativos que se generan al ambiente, dichas actividades hoy por hoy, se han convertido en un negocio que emplea a miles de personas, y genera ingresos. Se han convertido en actividades con amplia proyección de crecimiento a nivel mundial y de ahí el interés por internacionalizar dichos bienes y servicios. El Sector Medioambiental, cuenta con una clasificación que permite distinguir los diferentes subsectores que lo conforman, existen varios estudios enfocados principalmente a mostrar el nivel de empleo que cada subsector genera y el nivel de conocimiento y especialización que se requiere en cada uno.

En un principio se gestó la inquietud por saber como se desarrollaría el sector económico del medioambiente en Colombia, sin embargo, para lograr dar solución a dicho interrogante, es importante plantear una base teórica que funcione como guía en el desarrollo de la investigación. De modo que el objetivo que se plantea es el de realizar el estado del arte del sector económico del medioambiente en Europa y Colombia.

Sabiendo que en el momento el país de referencia sobre el cual se encontró la información del sector emergente es España, me atrevería a afirmar que es España el país pionero, sin embargo con la intención de lograr validar la información encontrada al respecto se pretende realizar el estado del arte en toda Europa, de manera que se logre un punto de comparación y revalidación del país pionero sobre el cual se van a enfocar los esfuerzos de recolección bibliográfica del tema del sector económico del medio ambiente en Europa. Y en Colombia porque la idea es identificar información sobre el tema, su dinámica, evolución y tendencia.

La investigación es de tipo exploratorio, ya que se busca obtener una visión general de tipo aproximativo, respecto al tema del sector económico del medio ambiente, debido a que ha sido un tema poco explorado y reconocido en Colombia, empleando un método histórico, debido a que se requiere tener el conocimiento de las distintas etapas o sucesos que dieron origen al sector económico del medio ambiente, conocer su evolución, desarrollo, y las etapas principales de su desenvolvimiento y las conexiones históricas fundamentales. Mediante el método histórico se busca analizar la trayectoria concreta de la teoría relacionada con el sector, su condicionamiento a los diferentes períodes dela historia.

Lo anterior, teniendo en cuenta el estado del arte se desarrolla en 2 fases: la fase heurística en la que se efectúa la búsqueda y recopilación de las fuentes de información y la fase hermenéutica, en la cual cada una de las fuentes 
investigadas se leerá, se analizará, se interpretará y se clasificará de acuerdo con su importancia dentro del trabajo de investigación. A partir de allí, se seleccionarán los puntos fundamentales y se indicarán el o los instrumentos diseñados para sistematizar la información bibliográfica e infográfica acopiada.

\section{Como resultados preliminares se encuentran:}

-En España el sector cuenta con una clasificación de aproximadamente 10 subsectores cada uno con su respectivo nivel de especialización; en Colombia lo más cercano a una clasificación de actividades productoras de bienes y servicios ambientales se encuentra en el marco del Plan Estratégico Nacional de Mercados Verdes (PENMV), cuyo fin es impulsar el tema de manera transversal a los demás sectores productivos y para que dichas actividades tengan un reconocimiento como iniciativas ambientalmente sostenible como son los productos y servicios verdes.

-España es un denominado país desarrollado, por lo tanto el nivel de ingresos de la población es alto, sumándole a esto la creciente preocupación por la preservación del medio ambiente, ha hecho que las personas demanden calidad ambiental, factor que se ha convertido casi en una exigencia; en otras palabras el nivel de desarrollo de un pás y de cultura es directamente proporcional con el grado de inversión en bienes y servicios del sector medioambiental.

-Además de lo descrito anteriormente, las actividades del sector medioambiental se encuentran impulsadas por normativas cada vez más estrictas que tienen los mecanismos adecuados para hacerlos cumplir "Existe un reconocimiento por parte de la administración de la importancia en el desarrollo de dichas actividades para fomentar un desarrollo sostenible en estas economías. De la misma manera, el marcado compromiso por mantener la calidad del recurso natural, por parte del sector público, privado y por supuesto de la sociedad civil, permiten una creciente demanda por los bienes y servicios medioambientales.

-Los problemas en materia ambiental a nivel mundial se están saliendo de nuestras manos (como el calentamiento global), y la preocupación por ello es creciente. De ahí que los países industrializados que a propósito son los mayores generadores de contaminación, presenten una amplia trayectoria en la búsqueda de soluciones que contrarresten el impacto negativo al medio ambiente.

-Es así como en la búsqueda por mantener un desarrollo sostenible, han surgido una serie de actividades medioambientales que no sólo están mitigando los daños al ambiente y propendiendo por la protección y el mantenimiento de los recursos naturales, sino que también se han consolidado como fuentes importantes de ingresus y de crecimiento económico. 
-Actualmente, muchos de estos llamados países desarrollados se encuentran iniciando un proceso de internacionalización de los servicios medioambientales, buscando países estratégicos como Chile, donde el tema ambiental ha recibido especial atención con la puesta en marcha de normativas mas estrictas, por lo que se convierte en un excelente lugar para las empresas extranjeras que buscan expandir su negocio. En este caso, Chile se convertiría en un país estratégico para que las multinacionales se expandan al resto de Latinoamérica, a medida que en cada país se fortalezca la participación de la administración en el tema medioambiental.

-Ahora bien, aunque en Colombia se cuenta con el programa de Mercados Verdes, las normativas en materia ambiental aun son débiles; si se pretende entrar en el juego, es importante que se implementen estrategias que permitan no solo modificar la legislación, de manera que se fortalezcan las actividades del sector y permita prepararnos para ser competitivos ante la oferta extranjera.

Lo anterior simplemente es un panorama general, que requiere de un estudio profundo que permita determinar la solución o la respuesta de raíz. Tener conocimiento de cómo funciona el sector medioambiental en los denominados países desarrollados simplemente sirve de referente, pues esto no quiere decir que las políticas implementadas allí funcionen para los países en vías de desarrollo como Colombia, es fundamental que a la hora de proponer las directrices se tenga en cuenta el contexto colombiano, las características culturales y político-económicas de nuestro país.

Se espera generar interés sobre el tema y vincular a más investigadores que generen nuevas ideas sobre el mismo y con los cuales se pueda validar el conocimiento generado con este tema poco explorado y que es de gran importancia sobre todo por los cambios sociales y económicos que genera a nivel mundial.

\section{Referencias bibliográficas e infográficas:}

- NEIRA SIMIJACA, Juan Alonso. Desarrollo Sostenible, Paradigma siglo XXI. ¿Realidad o Ilusión? Instituto de Cultura de Boyacá. Director editorial: Guillermo Velásquez Forero. Tunja, 2001. $21 \mathrm{p}$.

- VARAS CASTELLON, Juan Ignacio. Economía del Medio Ambiente en América Latina. Alfaomega Grupo Editor, S.A., 1999. 30-31 p.

- VEGA MORA, Leonel. Gestión medioambiental, un Enfoque Sistémico para la Protección Global e Integral del Medio Ambiente. Bogotá: TM Editores, 1999. 1-21 p. - Microsoft Encarta 2008. 1993-2007 Microsoft Corporation. Reservados todos los derechos.

- REYERO SUAREZ, Fernando. Retos del Sector Medioambiental y su Proyección Internacional. Boletín Económico de ICE N² 2823, del 8 al 14 de noviembre de 2004. 
Disponible en: http://www.revistasice.com/cmsrevistasICE/pdfs/

- El EMPLEO MEDIOAMBIENTAL EN ESPAÑA

http://www.ecoempleo.com/downloads/empleoambiental/spain/1/0 Iintro.pdf

- SECTORES ECONOMICOS EMERGENTES EN ANDALUCIA

http ://www ,cea .es/portalcea/pymes/creacion_empresa/sectores. aspx

- La industria medioambıental española mueve 10.000 millones cada año, según el

ICEXhttp://www.consumer_es/web/es/medio_amblente/2003/09/29/66126.phpMinister io de Ambiente, Vivienda y Desarrollo

Territorialhttp://www. mi nambiente gov. co/contenido/contenido.aspx?catID =15 1\& conID $=293$

\section{LA ADMINISTRACIÓN COMO ELEMENTO FUNDAMENTAL DEL DESARROLLO HUMANO}

\section{Nancy Paola Ramírez Becerra}

Grupo Construyendo Comunidad Educativa

Desde tiempos muy remotos el hombre siempre se ha preocupado por estar a la van guardia y ser pionero en todas las actividades que realiza. En un momento antiguo podemos darnos cuenta que las ideas eran mas avanzadas que el hombre, pero ahora es el hombre quien vive mas que las ideas. "El pensamiento Administrativo esta condicionado por esa realidad y generación sobre el acto administrativo se produce en lapsos cada vez menores." ${ }^{\text {"1 }}$

No solo esto se ve reflejado en estos tiempos sino, cuando aun las antiguas civilizaciones americanas no habían sido gobernadas por las colonias españolas. Tanto lo Mayas como los Aztecas y los Incas tuvieron que verse envueltos en un proceso de planeación, dirección y control de sus tribus. Ellos eran excelentes administradores puesto que a diario estaban en condiciones de poner en práctica sus conocimientos de agricultura, la pesca, la artesanía y muchas actividades que requerían de mucha organización para poder sobrevivir.

En este instante es el mejor ejemplo que tenemos de Administración como ciencia avanzada en la vida del hombre primitivo. Es valido aclarar que en estas antiguas civilizaciones el que tenía la voz de mando era el jefe de la tribu. El era quien tomaba las decisiones. Prácticamente lo podríamos comparar con el gerente de hoy. Un ser dinámico, con mucha astucia, capaz de liderar procesos

'HERNANDEZ YRODRIGUEZ, Sergio. Fundamentos de Administración. Pág. 51 